\title{
Behavioral differences between killer and nonkiller rats
}

\author{
B. MICHAEL THORNE, ART S. PATTERSON, and JEFF S. TOPPING \\ Mississippi State L'nirersity, Mississippi State, Mississippi 39762
}

\begin{abstract}
Killer and nonkiller rats were compared on the following behavioral measures: reactivity to handling, open-field activity divided into the number of squares traversed and rearing, defecation in the open field, and learning and retention of a discriminated avoidance response. In contrast to certain other reports, killer rats differed from nonkillers only in the number of rearings in the open field. On the basis of this study, killers do not appear to be more reactive than nonkillers.
\end{abstract}

In view of the enormous amount of interest in the muricidal response of the domestic rat, it is surprising that more effort has not been devoted to comparing killer and nonkiller rats. In the few comparisons that have been made, contradictory results have often been seen. For example, while Goldberg and Salama (1969) found higher levels of norepinephrine in killer rats than in nonkillers, Leaf, Lerner, and Horovitz (1969) reported that injections of norepinephrine into the amygdala of killers suppressed killing.

When comparing killer and nonkiller rats on behavioral indices other than the killing response, some researchers have noted differences while others have not. For example, Nováková, Flandera, and Sandritter (1974) have reported a variety of behavioral differences that could be summarized in terms of their distinction between excitable and nonexcitable rats. Thus, killer rats (excitable type) were found to be less able to habituate exploratory behavior and to exhibit more horizontal activity in an exploration test. In addition, the amount of time taken to acquire an auditory conditioned reflex was greater in the killer rats. The authors concluded that "killers have a lowered capacity to adapt to a new environment and to solve more complicated situations in life" (p. 732). Similarly, Vergnes. Boehrer, and Karli (1974) have reported that killer rats show a higher level of emotional responsiveness, at least as measured by boluses in an open-field test.

Knutson and Hynan (1973), however, found that killers and nonkillers did not differ with respect to shock-induced fighting. This finding would seem to contradict reports of increased emotional reactivity in killers.

The present study was designed to compare killer and nonkiller rats on a variety of responses that should reflect increased reactivity. Specifically, assessment was made of handling characteristics, open-field behavior with a differentiation into horizontal and vertical activity based on the report of Nováková et al. (1974), conditionability as measured by discrimination learning in a two-choice situation motivated by escape from

The authors would like to express appreciation for the assistance of Frank Cooper, Russell Gaines, and Mike Thompson. Send reprint requests to: Michael Thorne, P. O. Drawer PF, Mississippi State, Mississippi 39762. footshock and retention of the discrimination task following a 40-day interval.

\section{METHOD}

\section{Subjects}

The subjects were 26 adult male hooded rats of the Long-Evans strain. Breeding stock of the animals was originally obtained from Research Animals, Inc. (Braddock, Pennsylvania). All subjects had been used in a previous study involving muricidal tests and were assigned to either the killer (Group K) or the nonkiller (Group NK) group on the basis of a screening test for consistent killing. The screening test was given prior to all other behavioral tests and was administered by an experimenter who was not involved in the rest of the study. Thus, subsequent behavioral tests were administered by researchers who were unaware of whether or not their subjects were killers.

All subjects were singly housed in cages measuring $17.78 \times 25.40 \times 17.78 \mathrm{~cm}$ and were given ad-lib food and water.

\section{Apparatus}

The apparatus used to assess locomotor activity was an open-field box measuring $76.2 \times 76.2 \times 25.4 \mathrm{~cm}$. The entire box was painted flat black, and the floor was divided by white lines into 25 equal squares. Hardware cloth covered the top.

The discrimination apparatus was a Thompson-Bryant two-choice box from which the choice chamber had been removed, leaving only a startbox and a goalbox. The startbox had a grid floor through which footshock could be administered to motivate the animal. A Plexiglas door separated the start area from a $7.6-\mathrm{cm}$ grid in front of two openings into the goalbox. The doors to the goalbox were blocked by $10.2 \times 16.5 \mathrm{~cm}$ stimulus cards. Each stimulus card consisted of heavy posterboard on which was pasted either a piece of white or a piece of black construction paper. In order to prevent the animals from using olfactory cues to solve the discrimination, the cards were inserted into clear plastic sleeves which were washed with water after the testing of each animal. Painted gray cards were used in preliminary training.

\section{Procedure}

The screening procedure consisted of mousekilling tests on 2 consecutive days. An albino mouse was placed into the home cage of each rat and removed $24 \mathrm{~h}$ later to be replaced by a second mouse. Animals that killed a mouse on each of the 24-h tests were assigned to Group $\mathrm{K}$ while rats failing to kill on both tests were put into Group NK. Five subjects that killed on one test but not the other were discarded, leaving an $N$ of 21 of which 11 were killers and 10 were nonkillers.

liollowing the killing tests, all animals were given 5-day tests of handling characteristics and open-field activity. Limotionality was rated on a five-component scale moditied from the scale 
reported by King (1958). The components were as follows: (1) reaction to a pencil near the perioral region, (2) reaction to a pencil tap on the flank, (3) ease of capture from the home cage, (4) resistance to handling, and (5) amount of vocalization during testing. Each component was rated on a four-point scale (0-3), and each animal was given a daily total based on the sum of the ratings on the five components. Further details of testing may be found in Thorne, Aaron, and Latham (1973).

Immediately following the rating of handling characteristics, each animal was placed in the center of the open-field apparatus, and the number of squares traversed in a 1-min period was recorded. During the open-field test, all squares entered or crossed by the rats' hind feet were counted. In addition, the number of times the animals reared up (i.e., assumed a bipedal posture) was noted. Finally, the number of boluses was counted.

Reliability checks on the rating and counting procedures were made on several occasions through the use of an independent observer. A correlation coefficient based upon the daily ratings of handling by two observers was found to be $r=+.66, p<.05$. Even higher correlations were found between observers with respect to the activity measures with an $r=+.98$ for both the number of squares traversed and for the number of rearings.

On the 3rd day following completion of the handling and activity tests, training began on the discrimination tasks. Preliminary training consisted of five trials in which an animal was forced to leave the startbox and push aside a gray card in order to enter the goalbox. On the day following preliminary training, practice on the discrimination task (white-black) began. On each trial, each subject was placed into the startbox for $5 \mathrm{sec}$ during which the Plexiglas door separating the start area from the discriminanda was lowered. After elevation of the door, each subject was given approximately $15 \mathrm{sec}$ in which to make a choice. If the rat chose the black card, a mild footshock was administered, whereas choice of the white card permitted the animal to enter the goalbox. The position of the cards, but not the plastic sleeves, was varied according to a modified Gellerman sequence, and a correction procedure was employed. Animals were given 10 trials/day, with an intertrial interval of approximately $1 \mathrm{~min}$, until a criterion of nine correct responses in 1 day was attained. The number of errors an animal made prior to the day it reached criterion constituted the measure of learning ability.

Following a rest interval of 40 days, all subjects were tested for retention by relearning the original discrimination. A percent savings score was calculated for each subject.

\section{RESULTS AND DISCUSSION}

One subject from Group $\mathrm{K}$ died during the discrimination learning task, and his data was not included in the analysis. An analysis of handling characteristics was made by comparing the 5-day totals for each animal from the two groups. By this measure, Group $\mathrm{K}$ animals were not significantly different from nonkillers (Group $\mathrm{K}, \overline{\mathrm{X}}=5.4$; Group NK, $\overline{\mathrm{X}}=3.8$ ). In actuality, all animals were very easy to handle, with the maximum 5-day total being 14 out of a possible score of 75. It is possible that 1 st-day totals for Group $\mathrm{K}$ subjects were higher than for Group NK rats and that rapid habituation to handling masked the initial difference. However, comparison of 1 st-day totals for the groups did not reveal a significant difference.

Killers and nonkillers did not differ in terms of open-field activity when comparison was made of the 5-day totals (Group K, $\overline{\mathrm{X}}=83.6$; Group NK, $\overline{\mathrm{X}}=71.7$ ). The groups were significantly different in terms of rearings, with killers rearing more when 5-day totals were compared (Group K, $\overline{\mathrm{X}}=29.3$; Group NK, $\bar{X}=20.8 ; t=2.53, p<.05)$. There was no evidence for habituation to the open-field apparatus, but this was not unexpected since each animal was in the apparatus for a total of $5 \mathrm{~min}$. The groups did not differ in the number of boluses excreted during testing (Group K, 5-day $\overline{\mathrm{X}}=9.1$; Group NK, 5-day $\overline{\mathrm{X}}=10.1$ ).

The two groups performed almost identically on both the original learning and the retention of the brightness discrimination task. Thus, killer rats required a mean of 14 errors to learn the task (range: $8-26$ ) while nonkillers required an average of 14.2 errors (range: 10-27). Retention was quite good following the 40-day rest period (Group K, $\bar{X}=87.3 \%$; Group NK, $\bar{X}=83.9 \%$ ).

From the results of this study, it is obvious that little difference in the behavior of killers and nonkillers was seen. The one significant difference we found, i.e., Group K had more rearings in an open field, was in the opposite direction from that seen by Lat and cited in Novakova et al. (1974). Based on the results of the present study, we totally disagree with the statement of Novakova et al. concerning the excitability and lack of adaptability of killer rats.

While most of the results of the study by Vergnes et al. (1974) agree with our findings, e.g., they found no difference between killers and nonkillers in terms of locomotor activity, the finding of increased boluses in the second of two open-field tests led them to conclude that killers showed a higher level of emotionality in a novel environment. Since other comparisons in the same study failed to differentiate between killers and nonkillers, a more conservative conclusion would have been that the significant difference in boluses was not very meaningful in light of the number of tests performed. In previous studies in this laboratory, we have frequently found bolus count to be unrelated to other measures of emotionality and did not find a difference between killers and nonkillers on this measure.

In summary, to the extent that the behavioral measures employed in the present experiment reveal differences in reactivity, the conclusions reached by Nov́aková et al. (1974) are unjustified. Killer rats and nonkillers do not differ in terms of handling characteristics, number of squares traversed in an open field, or learning and retention of a discrimination problem motivated by escape from footshock. The difference in terms of rearing behavior in the open-field test could be interpreted as indicating that killers have a greater tendency to explore and are thus less, not more, reactive than nonkillers in a novel environment.

\section{REFERENCES}

Goldberg, M. E., \& Salama, A. I. Norepinephrine turnover and brain monoamine levels in aggressive mouse-killing rats. Biochemical Pharmacology, 1969, 18, 532-534.

King, F. A. Effects of septal and amygdaloid lesions on emotional behavior and conditioned avoidance responses in 
the rat. Journal of Nervous and Mental Diseases, 1958, 126 , $57-63$.

Knutson, J. F.. \& Hynan, M. T. Predatory aggression and irritable aggression: Shock-induced fighting in mouse-killing rats. Phy siology and Behavior, $1973,11,113-115$

Leaf, R. C., Lerner, L., \& Horovitz, Z. P. Role of the amygdala in the pharmacological and endocrinological manipulation of aggression. In S. Garattini and E. B. Sigg (Eds.), Aggressive behavior. New York: Wiley, 1969.

Nováková, V., Flandera, V., \& Sandritter, W. Aggressive rats: Some properties of learning, memory and of the limbic system. Pharmacology Biochemistry and Behavior, 1974, 2, $729-733$.
Thorne, B. M., Aaron, M., \& Latham, E. E. Effects of olfactory bulb ablation upon emotionality and muricidal behavior in four rat strains. Joumal of Comparative and Physiological Psychology, 1973, 84, 339-344.

Vergnes, M. Boehrer, A., \& Karli, P. Interspecific aggressiveness and reactivity in mouse-killing and nonkilling rats: Compared effects of olfactory bulb removal and raphé lesions. Aggressive Behavior, 1974, 1, 1-16.

(Received for publication May 8, 1975.) 